\title{
Recent Advances and Future Challenges for Artificial Neural Systems in Geotechnical Engineering Applications
}

\author{
Mohamed A. Shahin, ${ }^{1}$ Mark B. Jaksa, ${ }^{2}$ and Holger R. Maier ${ }^{2}$ \\ ${ }^{1}$ Department of Civil Engineering, Curtin University of Technology, Perth, WA 6845, Australia \\ ${ }^{2}$ School of Civil, Environmental and Mining Engineering, University of Adelaide, Adelaide, SA 5005, Australia \\ Correspondence should be addressed to Mohamed A. Shahin, m.shahin@curtin.edu.au
}

Received 28 April 2009; Accepted 1 September 2009

Recommended by Frederic Maire

Artificial neural networks (ANNs) are a form of artificial intelligence that has proved to provide a high level of competency in solving many complex engineering problems that are beyond the computational capability of classical mathematics and traditional procedures. In particular, ANNs have been applied successfully to almost all aspects of geotechnical engineering problems. Despite the increasing number and diversity of ANN applications in geotechnical engineering, the contents of reported applications indicate that the progress in ANN development and procedures is marginal and not moving forward since the mid-1990s. This paper presents a brief overview of ANN applications in geotechnical engineering, briefly provides an overview of the operation of ANN modeling, investigates the current research directions of ANNs in geotechnical engineering, and discusses some ANN modeling issues that need further attention in the future, including model robustness; transparency and knowledge extraction; extrapolation; uncertainty.

Copyright ( $) 2009$ Mohamed A. Shahin et al. This is an open access article distributed under the Creative Commons Attribution License, which permits unrestricted use, distribution, and reproduction in any medium, provided the original work is properly cited.

\section{Introduction}

Artificial neural networks (ANNs) are well suited to model the complex behavior of most geotechnical engineering materials which, by their very nature, exhibit extreme variability. ANNs have also demonstrated superior predictive ability when compared with traditional methods. Since the early 1990s, ANNs have been applied successfully to virtually every problem in geotechnical engineering. In this section, post-2001 applications of ANNs in geotechnical engineering are briefly examined, and interested readers are referred to Shahin et al. [1], where the pre-2001 papers are reviewed in some detail.

The behavior of deep (pile) and shallow foundations in soils is complex, uncertain, and not yet entirely understood. This fact has encouraged many researchers to apply the ANN technique to the prediction of the behavior of foundations. For example, ANNs have been used extensively for modeling the axial and lateral load capacities of deep foundations in compression and uplift, including driven piles [2-6], drilled shafts $[7,8]$, and ground anchor piles $[9,10]$. The prediction of behavior of shallow foundations has also been investigated, including settlement estimation [11-16] and bearing capacity [17-19].

Classical constitutive modeling based on elasticity and plasticity theories has limited capability to simulate properly the behavior of geomaterials. This is attributed to reasons associated with the formulation complexity, idealization of material behavior, and excessive empirical parameters [20]. In this regard, many neural networks have been proposed as a reliable and practical alternative to model the constitutive monotonic and hysteretic behavior of geomaterials [21-29].

Geotechnical properties and behavior of soils are controlled by factors such as mineralogy; fabric; pore water, and the interactions of these factors are difficult to establish solely by traditional statistical methods due to their interdependence [30]. Based on the application of ANNs, methodologies have been developed for estimating several soil properties, including the preconsolidation pressure [31], shear strength and stress history [30, 32-37], swell pressure $[38,39]$, lateral earth pressure [40], compaction characteristics and permeability [41,42], soil composition and classification $[43,44]$, and properties of soil dynamics $[45,46]$. 


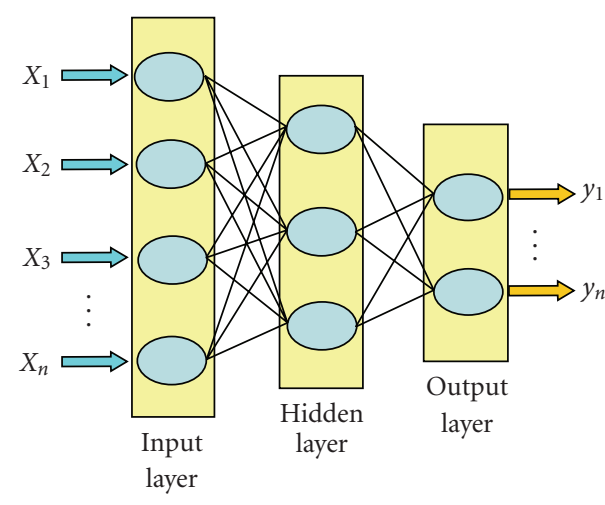

Artificial neural network

(a)

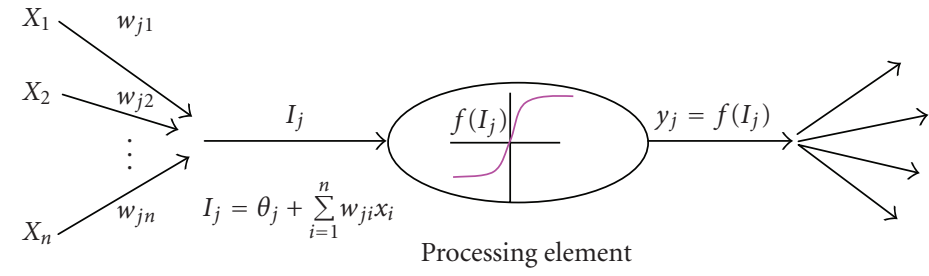

(b)

FIgUre 1: Typical structure and operation of ANNs.

Liquefaction during earthquakes is one of the very dangerous ground failure phenomena that can cause a large amount of damage to most civil engineering structures. Although the liquefaction mechanism is well known, the prediction of liquefaction potential is very complex [47]. This fact has attracted many researchers to investigate the applicability of ANNs for predicting liquefaction [47-55].

Other applications of ANNs in geotechnical engineering include earth retaining structures [56], dams [57, 58], blasting [59], mining [60], environmental geotechnics [61], rock mechanics [62-67], site characterization [68], tunnels and underground openings [69-74], slope stability and landslides [71, 75-79], and deep excavation [80].

\section{Brief Overview of Artificial Neural Networks}

Many authors have described the structure and operation of ANNs (e.g., [81, 82]), and whilst a comprehensive description of ANNs is beyond the scope of this paper, it is useful to provide a brief overview. ANNs are a data driven artificial intelligence approach that attempts to mimic, in a very simplistic way, the cognition capability of the human brain. ANNs learn by examples of data inputs and outputs presented to them so that the subtle functional relationships among the data are captured, even if the underlying relationships are unknown or the physical meaning is difficult to explain. This is in contrast to most traditional empirical and statistical methods, which need prior knowledge about the nature of the relationships among the data. This is one of the main benefits of ANNs when compared with most empirical and statistical methods.

Typically, the architecture of ANNs consists of a series of processing elements (PEs), or nodes, that are usually arranged in layers: an input layer, an output layer, and one or more hidden layers, as shown in Figure 1.

The input from each PE in the previous layer $x_{i}$ is multiplied by an adjustable connection weight $w_{j i}$. At each $\mathrm{PE}$, the weighted input signals are summed and a threshold value $\theta_{j}$ is added. This combined input $I_{j}$ is then passed through a nonlinear transfer function $f(\cdot)$ to produce the output of the PE $y_{j}$. The output of one PE provides the input to the PEs in the next layer. This process is summarized in (1) and (2) and illustrated in Figure 1.

$$
\begin{gathered}
I_{j}=\sum w_{j i} x_{i}+\theta_{j} \quad \text { summation, } \\
y_{j}=f\left(I_{j}\right) \quad \text { transfer. }
\end{gathered}
$$

The propagation of information in an ANN starts at the input layer, where the input data are presented. The network adjusts its weights on the presentation of a training data set and uses a learning rule to find a set of weights that will produce the input/output mapping that has the smallest possible error. This process is called "learning" or "training." Once the training phase of the model has been successfully accomplished, the performance of the trained model needs to be validated using an independent testing set. The main steps involved in the development of an ANN, as suggested by Maier and Dandy [83], are illustrated in Figure 2. Several of these steps are discussed in some depth in the following section.

\section{Current Development and Future Directions in Utilization of ANNs}

One issue that needs to be addressed in order to improve the performance of ANN models is the utilization of a systematic approach in their development. Such an approach needs to address major factors, including the determination of adequate model inputs, data division and preprocessing, choice of suitable network architecture, careful selection of some internal parameters that control the optimization method, stopping criteria, and model validation. For example, in relation to the second step of choice of data sets, method for data division, Shahin et al. [84] provided guidance using a geotechnical engineering example, and recommended the use of three, statistically consistent but independent data sets, one for each of training, testing, and validation. In this context, Shahin et al. [84] have introduced three approaches so that data division can be carried out in a systematic 


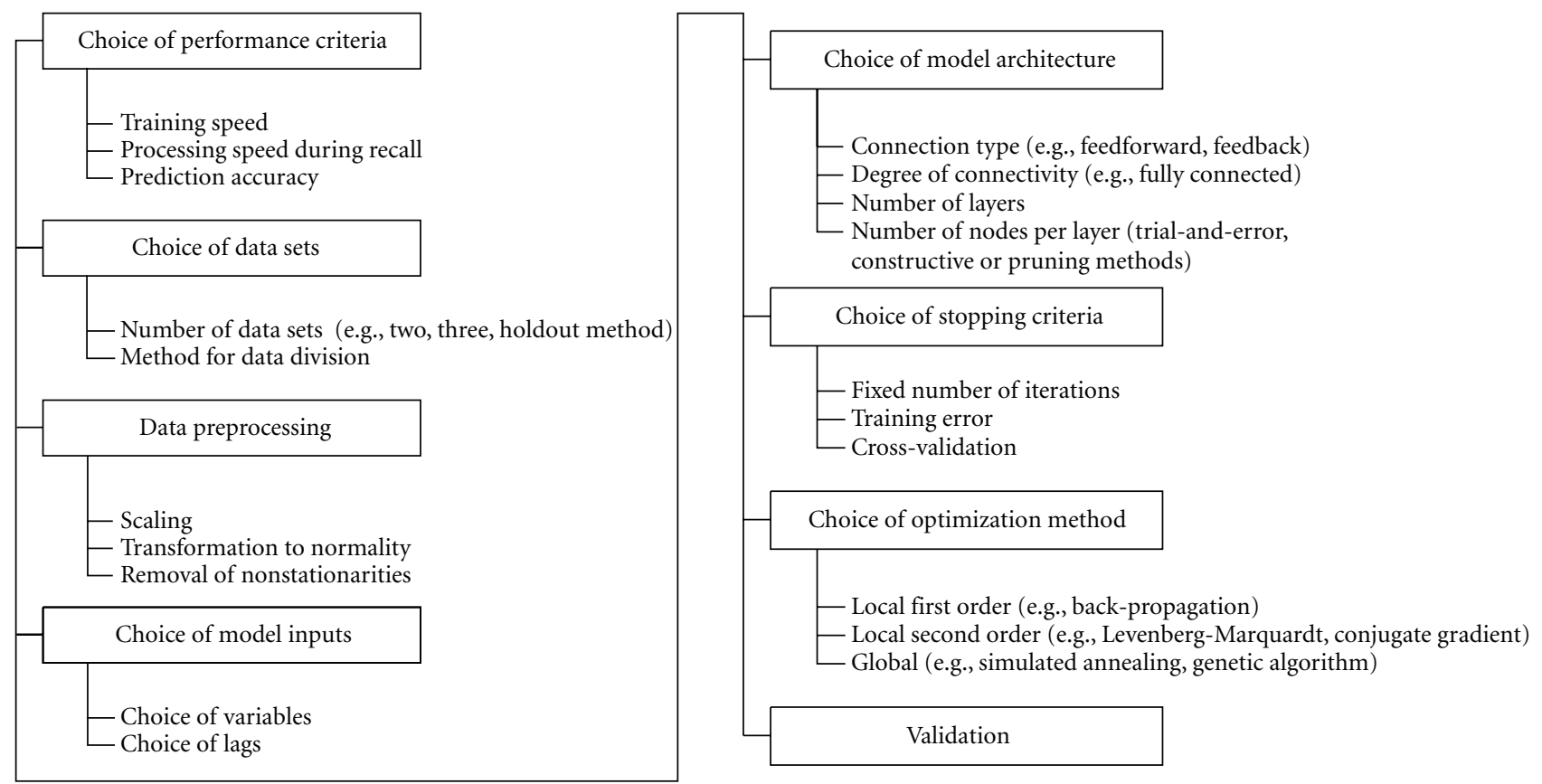

FIGURE 2: The main steps in ANN model development [83].

manner, including trial-and-error, self-organizing maps, and fuzzy clustering. For a detailed treatment of each of the steps in the model development process, interested readers are referred to Shahin et al. [85].

Other key issues in relation to ANN modeling that have received recent attention and require further research in the future include developing approaches that (i) ensure the development of robust models, (ii) increase model transparency and enable knowledge to be extracted from trained ANNs, (iii) improve extrapolation ability, and (iv) deal with uncertainty. Each of these is discussed in what follows.

3.1. Model Robustness. Model robustness is the predictive ability of ANN models to generalize over a range of data similar to that used for model training. Kingston et al. [86] stated that if "ANNs are to become more widely accepted and reach their full potential..., they should not only provide a good fit to the calibration and validation data, but the predictions should also be plausible in terms of the relationship modeled and robust under a wide range of conditions." and that "while ANNs validated against error alone may produce accurate predictions for situations similar to those contained in the training data, they may not be robust under different conditions unless the relationship by which the data were generated has been adequately estimated." This is in agreement with the investigation into the robustness of ANNs carried out by Shahin et al. [87] for a case study of predicting the settlement of shallow foundations on granular soils. Shahin et al. [87] found that good performance of ANN models on the data used for model calibration and validation does not guarantee that the models will perform well in a robust fashion over a range of data similar to those used in the model calibration phase. For this reason, Shahin et al. [87] proposed a method to test the robustness of the predictive ability of ANN models by carrying out a sensitivity analysis to investigate the response of ANN model outputs to changes in its inputs. The robustness of the model can then be determined by examining how well model predictions are in agreement with the known underlying physical processes of the problem in hand over a range of inputs. In addition, Shahin et al. [87] advised that the connection weights should be examined as part of the interpretation of ANN model behavior, using, for example, the method suggested by Garson [88]. On the other hand, Kingston et al. [86] adopted the connection weight approach of Olden et al. [89] for a case study in hydrological modeling in order to assess the relationship modeled by the ANNs, as Olden et al. [89] found that this approach provided the best overall methodology for quantifying ANN input importance in comparison to other commonly used methods, though with a few limitations.

Support vector machines (SVMs) are an alternative datadriven modeling approach that is claimed to provide better generalization capabilities and higher accuracy than ANNs and are therefore worth further consideration in relation to achieving improved model robustness [90]. Interested readers are referred to A. T. C. Goh and S. H. Goh [91] for a good overview of this technique. Recent applications of SVMs in the field of geotechnical engineering include the prediction of liquefaction potential $[90,91]$, analysis of slope stability [92], and modeling friction capacity of driven piles [93].

3.2. Model Transparency and Knowledge Extraction. Model transparency and knowledge extraction are the feasibility of interpreting ANN models in a way that provides insights into how model inputs affect outputs. Figure 3 shows the 


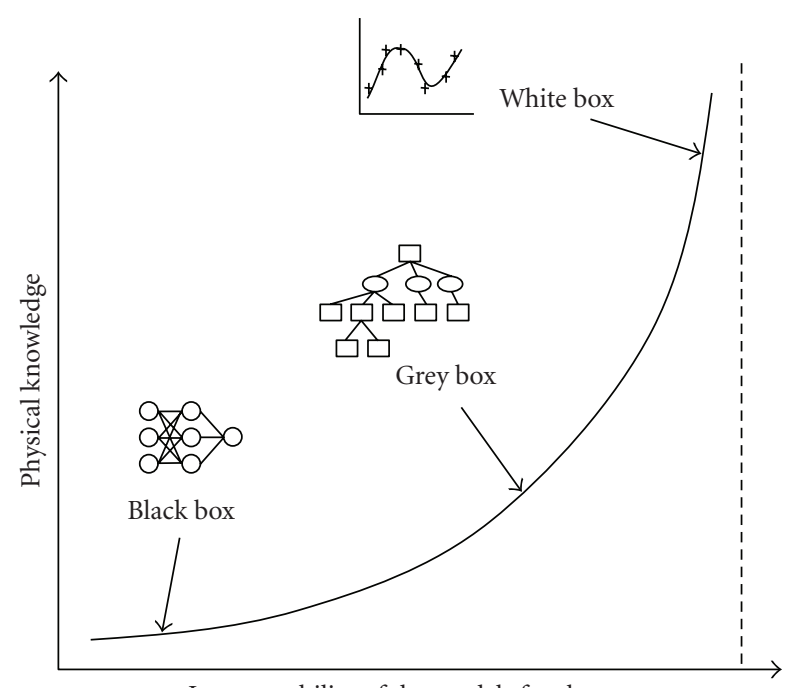

Interpretability of the models for the user

Figure 3: Graphical classification of modeling techniques (adapted from [94]).

classification of modeling techniques based on colors [94] in which the higher the physical knowledge used during model development, the better the physical interpretation of the phenomenon that the model provides to the user. It can be seen that the color coding of mathematical modeling can be classified into: white-, black-, and grey-box models, each of which can be explained as follows [95]. White-box models are systems that are based on first principles (e.g., physical laws) where model variables and parameters are known and have physical meaning by which the underlying physical relationships of the system can be explained. Black-box models are data-driven or regressive systems in which the functional form of relationships between model variables is unknown and needs to be estimated. Black-box models rely on data to map the relationships between model inputs and corresponding outputs rather than to find a feasible structure of the model input-output relationships. Grey-box models are conceptual systems in which the mathematical structure of the model can be derived, allowing further information of the system behavior to be resolved.

ANNs belong to the class of black-box models due to their lack of transparency and the fact that they do not consider nor explain the underlying physical processes explicitly. This is because the knowledge extracted by ANNs is stored in a set of weights that are difficult to interpret properly, and due to the large complexity of the network structure, ANNs fail to give a transparent function that relates the inputs to the corresponding outputs. Consequently, it is difficult to understand the nature of the input-output relationships derived. This issue has been addressed by many researchers with respect to hydrological engineering. For example, Jain et al. [96] examined whether or not the physical processes in a watershed were inherent in a trained ANN rainfallrunoff model. This was carried out by assessing the strengths of the relationships between the distributed components of the ANN model, in terms of the responses from the hidden nodes, and the deterministic components of the hydrological process, computed from a conceptual rainfall runoff model, along with the observed input variables, using correlation coefficients and scatter plots. They concluded that the trained ANN, in fact, captured different components of the physical process and a careful examination of the distributed information contained in the trained ANN can be informative about the nature of the physical processes captured by various components of the ANN model. Sudheer [97] performed perturbation analysis to assess the influence of each individual input variable on the output variable and found it to be an effective means of identifying the underlying physical process inherent in the trained ANN. Olden et al. [89], Sudheer and Jain [98], and Kingston et al. [99] also addressed this issue of model transparency and knowledge extraction.

In the context of geotechnical engineering, Shahin et al. [12] and Shahin and Jaksa [9] expressed the results of the trained ANNs in the form of relatively straightforward equations. This was possible due to the relatively small number of input and output variables, and hidden nodes. Neurofuzzy applications are another means of knowledge extraction that facilitate model transparency. Neurofuzzy networks use the fuzzy logic system to store knowledge acquired from a set of input variables $\left(x_{1}, x_{2}, \ldots, x_{n}\right)$ and the corresponding output variable $(y)$ in a set of linguistic fuzzy rules that can be easily interpreted, such as IF ( $x_{1}$ is high AND $x_{2}$ is low) THEN ( $y$ is high), $c=0.9$, where $(c=0.9)$ is the rule confidence, which indicates the degree to which the above rule has contributed to the output. Examples of such applications in geotechnical engineering include $\mathrm{Ni}$ et al. [100], Shahin et al. [16], Gokceoglu et al. [62], Provenzano et al. [19], and Padmini et al. [18].

A recent technique that belongs to the class of greybox models, and therefore does not suffer from the problem of model transparency and knowledge extraction, is genetic programming (GP). Several researchers (e.g., [34, 50, 101104]) have recently used the GP technique as an alterative to ANNs in order to obtain greatly simplified formulae for some geotechnical engineering problems. GP is a computing method that attempts to mimic the biological evolution of living organisms. GP makes use of the principles of genetic algorithms (GAs) for parameter optimization in which a population of expressions (or computer programs) for a function $F$, coded in tree structures of variable size, is generated and executed. The generated expressions are then modified by means of artificial evolution in order to perform a global search to arrive at the best fit mathematical expression for $F$ that solves a certain problem. Additional advantages of GP over ANNs are that the structure and network parameters of ANNs (e.g., number of hidden layers and their number of nodes, transfer functions, learning rate, etc.) should be identified a priori and are usually obtained using adhoc trial-and-error approaches. However, the number and combination of terms, as well as the values of GP modeling parameters, are all evolved automatically during model calibration. However, hybrid approaches can also be used, in which genetic algorithms are used to evolve 
optimal ANN structures and connection weight values. It should be noted that while white-box models provide maximum transparency, their construction may be difficult to obtain for many geotechnical engineering problems, where the underlying mechanism is not entirely understood.

3.3. Model Extrapolation. Model extrapolation is the ability of ANN models to predict well outside the range of the data used for model calibration. It is generally accepted that ANNs perform best when they do not extrapolate beyond the range of the data used for calibration [105-107]. Whilst this is not unlike other models, it is nevertheless an important limitation of ANNs, as it restricts their usefulness and applicability. Extreme value prediction is of particular concern in several areas of civil engineering, such as hydrological engineering, when floods are forecast, as well as in geotechnical engineering when, for example, liquefaction potential and the stability of slopes are assessed. Sudheer et al. [108] highlighted this issue and proposed a methodology, based on the Wilson-Hilferty transformation, for enabling ANN models to predict extreme values with respect to peak river flows. Their methodology yielded superior predictions when compared with those obtained from an ANN model using untransformed data.

3.4. Model Uncertainty. Finally, a further limitation of ANNs is that the uncertainty in the predictions generated is seldom quantified [109]. Failure to account for such uncertainty makes it impossible to assess the quality of ANN predictions, which severely limits their efficacy. In an effort to address this, a few researchers have applied Bayesian techniques to ANN training (e.g., [110-113]) in the context of hydrological engineering and Goh et al. [7] with respect to geotechnical engineering. Goh et al. [7] observed that the integration of the Bayesian framework into the back-propagation algorithm enhanced neural network prediction capabilities and provided assessment of the confidence associated with network predictions. Research to date has demonstrated the value of Bayesian neural networks, although further work is needed in the area of geotechnical engineering. Shahin et al. $[13,114]$ also incorporated uncertainty in the ANN process by developing a series of design charts expressing the reliability of settlement predictions for shallow foundations on cohesionless soils.

\section{Discussion and Conclusions}

In the field of geotechnical engineering, it is possible to encounter some types of problems that are very complex and not well understood. In this regard, ANNs provide several advantages over more conventional computing techniques. For most traditional mathematical models, the lack of physical understanding is usually supplemented by either simplifying the problem or incorporating several assumptions into the models. Mathematical models also rely on assuming the structure of the model in advance, which may be suboptimal. Consequently, many mathematical models fail to simulate the complex behavior of most geotechnical engineering problems. In contrast, ANNs are a data driven approach in which the model can be trained on input-output data pairs to determine the structure and parameters of the model. In this case, there is no need to either simplify the problem or incorporate any assumptions. Moreover, ANNs can always be updated to obtain better results by presenting new training examples as new data become available. These factors combine to make ANNs a powerful modeling tool in geotechnical engineering.

Despite the success of ANNs in geotechnical engineering and other disciplines, they suffer from some shortcomings that need further attention in the future, including model robustness, transparency and knowledge extraction, extrapolation, and uncertainty. In addition and according to Flood [115], ANNs in civil engineering, including geotechnical engineering, were used mostly as simple vector mapping devices for function modeling of applications that require rarely more than a few tens of neurons without higherorder structuring. Together, improvements in these issues will greatly enhance the usefulness of ANN models and will provide the next generation of applied artificial neural networks with the best way for advancing the field to the next level of sophistication and application. Until such an improvement is achieved, the authors agree with Flood and Kartam [105] that neural networks for the time being might be treated as a complement to conventional computing techniques rather than as an alternative or may be used as a quick check on solutions developed by more timeconsuming and in-depth analyses.

\section{References}

[1] M. A. Shahin, M. B. Jaksa, and H. R. Maier, "Artificial neural network applications in geotechnical engineering," Australian Geomechanics, vol. 36, no. 1, pp. 49-62, 2001.

[2] I. Ahmad, M. H. El Naggar, and A. N. Khan, "Artificial neural network application to estimate kinematic soil pile interaction response parameters," Soil Dynamics and Earthquake Engineering, vol. 27, no. 9, pp. 892-905, 2007.

[3] S. K. Das and P. K. Basudhar, "Undrained lateral load capacity of piles in clay using artificial neural network," Computers and Geotechnics, vol. 33, no. 8, pp. 454-459, 2006.

[4] A. M. Hanna, G. Morcous, and M. Helmy, "Efficiency of pile groups installed in cohesionless soil using artificial neural networks," Canadian Geotechnical Journal, vol. 41, no. 6, pp. 1241-1249, 2004.

[5] H. Ardalan, A. Eslami, and N. Nariman-Zadeh, "Piles shaft capacity from CPT and CPTu data by polynomial neural networks and genetic algorithms," Computers and Geotechnics, vol. 36, no. 4, pp. 616-625, 2009.

[6] M. A. Shahin, "Modelling axial capacity of pile foundations by intelligent computing," in Proceedings of the 2nd BGA International Conference on Foundations (ICOF '08), pp. 283294, IHS BRE Press, Dundee, Scotland, 2008.

[7] A. T. C. Goh, F. H. Kulhawy, and C. G. Chua, "Bayesian neural network analysis of undrained side resistance of drilled shafts," Journal of Geotechnical \& Geoenvironmental Engineering, vol. 131, no. 1, pp. 84-93, 2005. 
[8] M. A. Shahin and M. B. Jaksa, "Intelligent computing for predicting axial capacity of drilled shafts," in Proceedings of the International Foundation Congress and Equipment Expo (IFCEE '09), ASCE Geotechnical Special Publication, no. 186, pp. 26-33, Orlando, Fla, USA, 2009.

[9] M. A. Shahin and M. B. Jaksa, "Neural network prediction of pullout capacity of marquee ground anchors," Computers and Geotechnics, vol. 32, no. 3, pp. 153-163, 2005.

[10] M. A. Shahin and M. B. Jaksa, "Pullout capacity of small ground anchors by direct cone penetration test methods and neural networks," Canadian Geotechnical Journal, vol. 43, no. 6, pp. 626-637, 2006.

[11] Y.-L. Chen, R. Azzam, and F.-B. Zhang, "The displacement computation and construction pre-control of a foundation pit in Shanghai utilizing FEM and intelligent methods," Geotechnical and Geological Engineering, vol. 24, no. 6, pp. 1781-1801, 2006.

[12] M. A. Shahin, M. B. Jaksa, and H. R. Maier, "Artificial neural network-based settlement prediction formula for shallow foundations on granular soils," Australian Geomechanics, vol. 37, no. 4, pp. 45-52, 2002.

[13] M. A. Shahin, M. B. Jaksa, and H. R. Maier, "Neural network based stochastic design charts for settlement prediction," Canadian Geotechnical Journal, vol. 42, no. 1, pp. 110-120, 2005.

[14] M. A. Shahin, H. R. Maier, and M. B. Jaksa, "Predicting settlement of shallow foundations using neural networks," Journal of Geotechnical \& Geoenvironmental Engineering, vol. 128, no. 9, pp. 785-793, 2002.

[15] M. A. Shahin, H. R. Maier, and M. B. Jaksa, "Predicting settlement of shallow foundations using neural networks," Journal of Geotechnical \& Geoenvironmental Engineering, vol. 128, no. 9, pp. 785-793, 2002.

[16] M. A. Shahin, H. R. Maier, and M. B. Jaksa, "Settlement prediction of shallow foundations on granular soils using Bspline neurofuzzy models," Computers and Geotechnics, vol. 30, no. 8, pp. 637-647, 2003.

[17] Y. L. Kuo, M. B. Jaksa, A. V. Lyamin, and W. S. Kaggwa, "ANN-based model for predicting the bearing capacity of strip footing on multi-layered cohesive soil," Computers and Geotechnics, vol. 36, no. 3, pp. 503-516, 2009.

[18] D. Padmini, K. Ilamparuthi, and K. P. Sudheer, "Ultimate bearing capacity prediction of shallow foundations on cohesionless soils using neurofuzzy models," Computers and Geotechnics, vol. 35, no. 1, pp. 33-46, 2008.

[19] P. Provenzano, S. Ferlisi, and A. Musso, "Interpretation of a model footing response through an adaptive neural fuzzy inference system," Computers and Geotechnics, vol. 31, no. 3, pp. 251-266, 2004.

[20] H. Adeli, "Neural networks in civil engineering: 1989-2000," Computer-Aided Civil and Infrastructure Engineering, vol. 16, no. 2, pp. 126-142, 2001.

[21] I. A. Basheer, "Stress-strain behavior of geomaterials in loading reversal simulated by time-delay neural networks," Journal of Materials in Civil Engineering, vol. 14, no. 3, pp. 270-273, 2002.

[22] Q. Fu, Y. M. A. Hashash, S. Jung, and J. Ghaboussi, "Integration of laboratory testing and constitutive modeling of soils," Computers and Geotechnics, vol. 34, no. 5, pp. 330$345,2007$.

[23] G. Habibagahi and A. Bamdad, "A neural network framework for mechanical behavior of unsaturated soils," Canadian Geotechnical Journal, vol. 40, no. 3, pp. 684-693, 2003.
[24] Y. M. A. Hashash, S. Jung, and J. Ghaboussi, "Numerical implementation of a neural network based material model in finite element analysis," International Journal for Numerical Methods in Engineering, vol. 59, no. 7, pp. 989-1005, 2004.

[25] M. Lefik and B. A. Schrefler, "Artificial neural network as an incremental non-linear constitutive model for a finite element code," Computer Methods in Applied Mechanics and Engineering, vol. 192, no. 28-30, pp. 3265-3283, 2003.

[26] Y. M. Najjar and C. Huang, "Simulating the stress-strain behavior of Georgia kaolin via recurrent neuronet approach," Computers and Geotechnics, vol. 34, no. 5, pp. 346-361, 2007.

[27] M. A. Shahin and B. Indraratna, "Modeling the mechanical behavior of railway ballast using artificial neural networks," Canadian Geotechnical Journal, vol. 43, no. 11, pp. 11441152, 2006.

[28] M. Banimahd, S. S. Yasrobi, and P. K. Woodward, "Artificial neural network for stress-strain behavior of sandy soils: knowledge based verification," Computers and Geotechnics, vol. 32, no. 5, pp. 377-386, 2005.

[29] W. Gao, X. T. Feng, and Y. R. Zheng, "Identification of a constitutive model for geo-materials using a new intelligent bionics algorithm," International Journal of Rock Mechanics and Mining Sciences, vol. 41, supplement 1, pp. 454-459, 2004.

[30] Y. Yang and M. S. Rosenbaum, "The artificial neural network as a tool for assessing geotechnical properties," Geotechnical and Geological Engineering, vol. 20, no. 2, pp. 149-168, 2002.

[31] S. Çelik and Ö. Tan, "Determination of preconsolidation pressure with artificial neural network," Civil Engineering and Environmental Science, vol. 22, no. 4, pp. 217-231, 2005.

[32] S. J. Lee, S. R. Lee, and Y. S. Kim, "An approach to estimate unsaturated shear strength using artificial neural network and hyperbolic formulation," Computers and Geotechnics, vol. 30, no. 6, pp. 489-503, 2003.

[33] P. U. Kurup and N. K. Dudani, "Neural networks for profiling stress history of clays from PCPT data," Journal of Geotechnical \& Geoenvironmental Engineering, vol. 128, no. 7, pp. 569-579, 2002.

[34] B. S. Narendra, P. V. Sivapullaiah, S. Suresh, and S. N. Omkar, "Prediction of unconfined compressive strength of soft grounds using computational intelligence techniques: a comparative study," Computers and Geotechnics, vol. 33, no. 3, pp. 196-208, 2006.

[35] A. Baykasoglu, H. Güllü, H. Çanakçi, and L. Özbakir, "Prediction of compressive and tensile strength of limestone via genetic programming," Expert Systems with Applications, vol. 35, no. 1-2, pp. 111-123, 2008.

[36] W. Y. Byeon, S. R. Lee, and Y. S. Kim, "Application of flat DMT and ANN to Korean soft clay deposits for reliable estimation of undrained shear strength," International Journal of Offshore and Polar Engineering, vol. 16, no. 1, pp. 73-80, 2006.

[37] A. Kaya, "Residual and fully softened strength evaluation of soils using artificial neural networks," Geotechnical and Geological Engineering, vol. 27, no. 2, pp. 281-288, 2009.

[38] Y. Erzin, "Artificial neural networks approach for swell pressure versus soil suction behaviour," Canadian Geotechnical Journal, vol. 44, no. 10, pp. 1215-1223, 2007.

[39] I. Ashayeri and S. Yasrebi, "Free-swell and swelling pressure of unsaturated compacted clays; experiments and neural networks modeling," Geotechnical and Geological Engineering, vol. 27, no. 1, pp. 137-153, 2009. 
[40] S. K. Das and P. K. Basudhar, "Prediction of coefficient of lateral earth pressure using artificial neural networks," The Electronic Journal of Geotechnical Engineering, vol. 10, pp. 15, 2005.

[41] S. K. Sinha and M. C. Wang, "Artificial neural network prediction models for soil compaction and permeability," Geotechnical and Geological Engineering, vol. 26, no. 1, pp. 47-64, 2008

[42] A. H. Abdel-Rahman, "Predicting compaction of cohesionless soils using ANN," Ground Improvement, vol. 161, no. 1, pp. 3-8, 2008.

[43] P. U. Kurup and E. P. Griffin, "Prediction of soil composition from CPT data using general regression neural network," Journal of Computing in Civil Engineering, vol. 20, no. 4, pp. 281-289, 2006.

[44] B. Bhattacharya and D. P. Solomatine, "Machine learning in soil classification," Neural Networks, vol. 19, no. 2, pp. 186195, 2006.

[45] M. P. Romo and S. R. García, "Neurofuzzy mapping of CPT values into solid dynamic properties," Soil Dynamics and Earthquake Engineering, vol. 23, no. 6, pp. 473-482, 2003.

[46] S. R. García, M. P. Romo, and J. Figueroa-Nazuno, "Soil dynamic properties determination: a neurofuzzy system approach," Control and Intelligent Systems, vol. 34, no. 1, pp. $1-11,2006$.

[47] M. H. Baziar and A. Ghorbani, "Evaluation of lateral spreading using artificial neural networks," Soil Dynamics and Earthquake Engineering, vol. 25, no. 1, pp. 1-9, 2005.

[48] A. T. C. Goh, "Probabilistic neural network for evaluating seismic liquefaction potential," Canadian Geotechnical Journal, vol. 39, no. 1, pp. 219-232, 2002.

[49] A. M. Hanna, D. Ural, and G. Saygili, "Neural network model for liquefaction potential in soil deposits using Turkey and Taiwan earthquake data," Soil Dynamics and Earthquake Engineering, vol. 27, no. 6, pp. 521-540, 2007.

[50] A. A. Javadi, M. Rezania, and M. M. Nezhad, "Evaluation of liquefaction induced lateral displacements using genetic programming," Computers and Geotechnics, vol. 33, no. 4-5, pp. 222-233, 2006.

[51] K. Young-Su and K. Byung-Tak, "Use of artificial neural networks in the prediction of liquefaction resistance of sands," Journal of Geotechnical \& Geoenvironmental Engineering, vol. 132, no. 11, pp. 1502-1504, 2006.

[52] A. M. Hanna, D. Ural, and G. Saygili, "Evaluation of liquefaction potential of soil deposits using artificial neural networks," Engineering Computations, vol. 24, no. 1, pp. 516, 2007.

[53] M. S. Rahman and J. Wang, "Fuzzy neural network models for liquefaction prediction," Soil Dynamics and Earthquake Engineering, vol. 22, no. 8, pp. 685-694, 2002.

[54] C. H. Juang, H. Yuan, D.-H. Lee, and P.-S. Lin, "Simplified cone penetration test-based method for evaluating liquefaction resistance of soils," Journal of Geotechnical \& Geoenvironmental Engineering, vol. 129, no. 1, pp. 66-80, 2003.

[55] S. S. H. Khozaghi and A. J. A.-Z. Choobbasti, "Predicting of liquefaction potential in soils using artificial neural networks," Electronic Journal of Geotechnical Engineering, vol. 12C, 2007.

[56] G. T. C. Kung, E. C. L. Hsiao, M. Schuster, and C. H. Juang, "A neural network approach to estimating deflection of diaphragm walls caused by excavation in clays," Computers and Geotechnics, vol. 34, no. 5, pp. 385-396, 2007.
[57] Y.-S. Kim and B.-T. Kim, "Prediction of relative crest settlement of concrete-faced rockfill dams analyzed using an artificial neural network model," Computers and Geotechnics, vol. 35, no. 3, pp. 313-322, 2008.

[58] Y. Yu, B. Zhang, and H. Yuan, "An intelligent displacement back-analysis method for earth-rockfill dams," Computers and Geotechnics, vol. 34, no. 6, pp. 423-434, 2007.

[59] Y. Lu, "Underground blast induced ground shock and its modelling using artificial neural network," Computers and Geotechnics, vol. 32, no. 3, pp. 164-178, 2005.

[60] T. N. Singh and V. Singh, "An intelligent approach to prediction and control ground vibration in mines," Geotechnical and Geological Engineering, vol. 23, no. 3, pp. 249-262, 2005.

[61] J. Q. Shang, W. Ding, R. K. Rowe, and L. Josic, "Detecting heavy metal contamination in soil using complex permittivity and artificial neural networks," Canadian Geotechnical Journal, vol. 41, no. 6, pp. 1054-1067, 2004.

[62] C. Gokceoglu, E. Yesilnacar, H. Sonmez, and A. Kayabasi, "A neuro-fuzzy model for modulus of deformation of jointed rock masses," Computers and Geotechnics, vol. 31, no. 5, pp. 375-383, 2004.

[63] T. N. Singh, A. K. Verma, V. Singh, and A. Sahu, "Slake durability study of shaly rock and its predictions," Environmental Geology, vol. 47, no. 2, pp. 246-253, 2005.

[64] S. Ma, L.-H. Cao, and H.-Y. Li, "The improved neutral network and its application for valuing rock mass mechanical parameter," Journal of Coal Science and Engineering, vol. 12, no. 1, pp. 21-24, 2006.

[65] T. N. Singh, A. K. Verma, and P. K. Sharma, "A neuro-genetic approach for prediction of time dependent deformational characteristic of rock and its sensitivity analysis," Geotechnical and Geological Engineering, vol. 25, no. 4, pp. 395-407, 2007.

[66] V. B. Maji and T. G. Sitharam, "Prediction of elastic modulus of jointed rock mass using artificial neural networks," Geotechnical and Geological Engineering, vol. 26, no. 4, pp. 443-452, 2008.

[67] T. G. Sitharam, P. Samui, and P. Anbazhagan, "Spatial variability of rock depth in Bangalore using geostatistical, neural network and support vector machine models," Geotechnical and Geological Engineering, vol. 26, no. 5, pp. 503-517, 2008.

[68] N. Caglar and H. Arman, "The applicability of neural networks in the determination of soil profiles," Bulletin of Engineering Geology and the Environment, vol. 66, no. 3, pp. 295-301, 2007.

[69] C. Yoo and J.-M. Kim, "Tunneling performance prediction using an integrated GIS and neural network," Computers and Geotechnics, vol. 34, no. 1, pp. 19-30, 2007.

[70] A. G. Benardos and D. C. Kaliampakos, "Modelling TBM performance with artificial neural networks," Tunnelling and Underground Space Technology, vol. 19, no. 6, pp. 597-605, 2004.

[71] K. Neaupane and S. Achet, "Some applications of a backpropagation neural network in geo-engineering," Environmental Geology, vol. 45, no. 4, pp. 567-575, 2004.

[72] K. M. Neaupane and N. R. Adhikari, "Prediction of tunneling-induced ground movement with the multi-layer perceptron," Tunnelling and Underground Space Technology, vol. 21, no. 2, pp. 151-159, 2006.

[73] Y.-L. Chen, R. Azzam, T. M. Fernandez-Steeger, and L. Li, "Studies on construction pre-control of a connection aisle between two neighbouring tunnels in Shanghai by means of 3D FEM, neural networks and fuzzy logic," Geotechnical and Geological Engineering, vol. 27, no. 1, pp. 155-167, 2009. 
[74] A. Alimoradi, A. Moradzadeh, R. Naderi, M. Z. Salehi, and A. Etemadi, "Prediction of geological hazardous zones in front of a tunnel face using TSP-203 and artificial neural networks," Tunnelling and Underground Space Technology, vol. 23, no. 6, pp. 711-717, 2008.

[75] M. D. Ferentinou and M. G. Sakellariou, "Computational intelligence tools for the prediction of slope performance," Computers and Geotechnics, vol. 34, no. 5, pp. 362-384, 2007.

[76] A. T. C. Goh and F. H. Kulhawy, "Neural network approach to model the limit state surface for reliability analysis," Canadian Geotechnical Journal, vol. 40, no. 6, pp. 1235-1244, 2003.

[77] F. Mayoraz and L. Vulliet, "Neural networks for slope movement prediction," The International Journal of Geomechanics, vol. 2, no. 2, pp. 153-173, 2002.

[78] D. P. Kanungo, M. K. Arora, S. Sarkar, and R. P. Gupta, "A comparative study of conventional, ANN black box, fuzzy and combined neural and fuzzy weighting procedures for landslide susceptibility zonation in Darjeeling Himalayas," Engineering Geology, vol. 85, no. 3-4, pp. 347-366, 2006.

[79] H. B. Wang and K. Sassa, "Rainfall-induced landslide hazard assessment using artificial neural networks," Earth Surface Processes and Landforms, vol. 31, no. 2, pp. 235-247, 2006.

[80] Y. M. A. Hashash, C. Marulanda, J. Ghaboussi, and S. Jung, "Systematic update of a deep excavation model using field performance data," Computers and Geotechnics, vol. 30, no. 6, pp. 477-488, 2003.

[81] L. V. Fausett, Fundamentals Neural Networks: Architecture, Algorithms, and Applications, Prentice-Hall, Englewood Cliffs, NJ, USA, 1994.

[82] J. M. Zurada, Introduction to Artificial Neural Systems, West Publishing, Saint Paul, Minn, USA, 1992.

[83] H. R. Maier and G. C. Dandy, "Applications of artificial neural networks to forecasting of surface water quality variables: issues, applications and challenges," in Artificial Neural Networks in Hydrology, R. S. Govindaraju and A. R. Rao, Eds., pp. 287-309, Kluwer Academic Publishers, Dordrecht, The Netherlands, 2000.

[84] M. A. Shahin, H. R. Maier, and M. B. Jaksa, "Data division for developing neural networks applied to geotechnical engineering," Journal of Computing in Civil Engineering, vol. 18, no. 2, pp. 105-114, 2004.

[85] M. A. Shahin, M. B. Jaksa, and H. R. Maier, "State of the art of artificial neural networks in geotechnical engineering," Electronic Journal of Geotechnical Engineering, vol. 8, pp. 126, 2008 .

[86] G. B. Kingston, H. R. Maier, and M. F. Lambert, "Calibration and validation of neural networks to ensure physically plausible hydrological modeling," Journal of Hydrology, vol. 314, no. 1-4, pp. 158-176, 2005.

[87] M. A. Shahin, H. R. Maier, and M. B. Jaksa, "Investigation into the robustness of artificial neural network models for a case study in civil engineering," in Proceedings of the International Congress on Modelling and Simulation (MODSIM '05), pp. 79-83, Melbourne, Australia, 2005.

[88] G. D. Garson, "Interpreting neural-network connection weights," AI Expert, vol. 6, no. 7, pp. 47-51, 1991.

[89] J. D. Olden, M. K. Joy, and R. G. Death, "An accurate comparison of methods for quantifying variable importance in artificial neural networks using simulated data," Ecological Modelling, vol. 178, no. 3-4, pp. 389-397, 2004.
[90] M. Pal, "Support vector machines-based modelling of seismic liquefaction potential," International Journal for Numerical and Analytical Methods in Geomechanics, vol. 30, no. 10, pp. 983-996, 2006.

[91] A. T. C. Goh and S. H. Goh, "Support vector machines: their use in geotechnical engineering as illustrated using seismic liquefaction data," Computers and Geotechnics, vol. 34, no. 5, pp. 410-421, 2007.

[92] H.-B. Zhao, "Slope reliability analysis using a support vector machine," Computers and Geotechnics, vol. 35, no. 3, pp. 459467, 2008.

[93] P. Samui, "Prediction of friction capacity of driven piles in clay using the support vector machine," Canadian Geotechnical Journal, vol. 45, no. 2, pp. 288-295, 2008.

[94] O. Giustolisi, A. Doglioni, D. A. Savic, and B. W. Webb, "A multi-model approach to analysis of environmental phenomena," Environmental Modelling \& Software, vol. 22, no. 5, pp. 674-682, 2007.

[95] O. Giustolisi, "Using genetic programming to determine Chezy resistance coefficient in corrugated channels," Journal of Hydroinformatics, vol. 3, no. 6, pp. 157-173, 2004.

[96] A. Jain, K. P. Sudheer, and S. Srinivasulu, "Identification of physical processes inherent in artificial neural network rainfall runoff models," Hydrological Processes, vol. 18, no. 3, pp. 571-581, 2004.

[97] K. P. Sudheer, "Knowledge extraction from trained neural network river flow models," Journal of Hydrologic Engineering, vol. 10, no. 4, pp. 264-269, 2005.

[98] K. P. Sudheer and A. Jain, "Explaining the internal behaviour of artificial neural network river flow models," Hydrological Processes, vol. 18, no. 4, pp. 833-844, 2004.

[99] G. B. Kingston, H. R. Maier, and M. F. Lambert, "A probabilistic method for assisting knowledge extraction from artificial neural networks used for hydrological prediction," Mathematical and Computer Modelling, vol. 44, no. 5-6, pp. 499-512, 2006.

[100] S. H. Ni, P. C. Lu, and C. H. Juang, "A fuzzy neural network approach to evaluation of slope failure potential," ComputerAided Civil and Infrastructure Engineering, vol. 11, no. 1, pp. 59-66, 1996.

[101] X.-T. Feng, B.-R. Chen, C. Yang, H. Zhou, and X. Ding, "Identification of visco-elastic models for rocks using genetic programming coupled with the modified particle swarm optimization algorithm," International Journal of Rock Mechanics and Mining Sciences, vol. 43, no. 5, pp. 789-801, 2006.

[102] A. Johari, G. Habibagahi, and A. Ghahramani, "Prediction of soil-water characteristic curve using genetic programming," Journal of Geotechnical \& Geoenvironmental Engineering, vol. 132, no. 5, pp. 661-665, 2006.

[103] M. Rezania and A. Javadi, "A new genetic programming model for predicting settlement of shallow foundations," Canadian Geotechnical Journal, vol. 44, no. 12, pp. 14621472, 2007.

[104] I. Alkroosh, M. A. Shahin, and H. R. Nikraz, "Modelling axial capacity of bored piles using genetic programming technique," in Proceedings of the 3rd International GeoChiangmai Conference, pp. 113-120, Chiangmai, Thailand, 2008.

[105] I. Flood and N. Kartam, "Neural networks in civil engineering. I: principles and understanding," Journal of Computing in Civil Engineering, vol. 8, no. 2, pp. 131-148, 1994. 
[106] A. W. Minns and M. J. Hall, "Artificial neural networks as rainfall-runoff models," Hydrological Sciences Journal, vol. 41, no. 3, pp. 399-417, 1996.

[107] A. S. Tokar and P. A. Johnson, "Rainfall-runoff modeling using artificial neural networks," Journal of Hydrologic Engineering, vol. 4, no. 3, pp. 232-239, 1999.

[108] K. P. Sudheer, P. C. Nayak, and K. S. Ramasastri, "Improving peak flow estimates in artificial neural network river flow models," Hydrological Processes, vol. 17, no. 3, pp. 677-686, 2003.

[109] H. R. Maier and G. C. Dandy, "Neural networks for the prediction and forecasting of water resources variables: a review of modelling issues and applications," Environmental Modelling \& Software, vol. 15, no. 1, pp. 101-124, 2000.

[110] W. L. Buntine and A. S. Weigend, "Bayesian backpropagation,” Complex Systems, vol. 5, pp. 603-643, 1991.

[111] G. B. Kingston, M. F. Lambert, and H. R. Maier, "Bayesian parameter estimation applied to artificial neural networks used for hydrological modelling," Water Resources Research, vol. 41, Article ID W12409, 2005.

[112] G. MacKay, "A practical Bayesian framework for backpropagation networks," Neural Computation, vol. 4, pp. 448-472, 1992.

[113] G. B. Kingston, H. R. Maier, and M. F. Lambert, "Bayesian model selection applied to artificial neural networks used for water resources modeling," Water Resources Research, vol. 44, no. 4, Article ID W04419, 2008.

[114] M. A. Shahin, M. B. Jaksa, and H. R. Maier, "Stochastic simulation of settlement of shallow foundations based on a deterministic neural network model," in Proceedings of the International Congress on Modelling and Simulation (MODSIM '05), pp. 73-78, Melbourne, Australia, 2005.

[115] I. Flood, "Towards the next generation of artificial neural networks for civil engineering," Advanced Engineering Informatics, vol. 22, no. 1, pp. 4-14, 2008. 

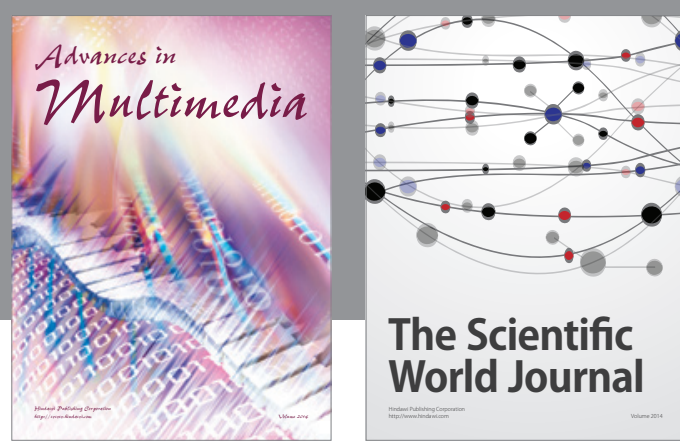

The Scientific World Journal
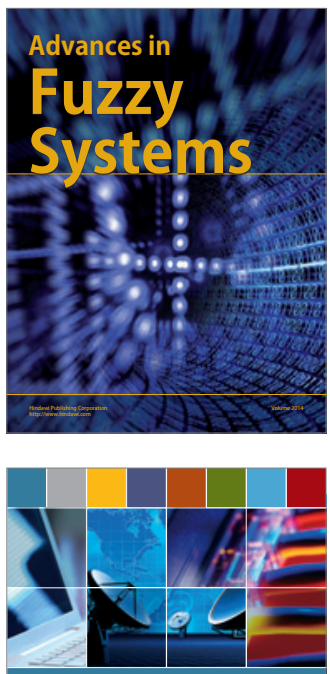

Computer Networks and Communications
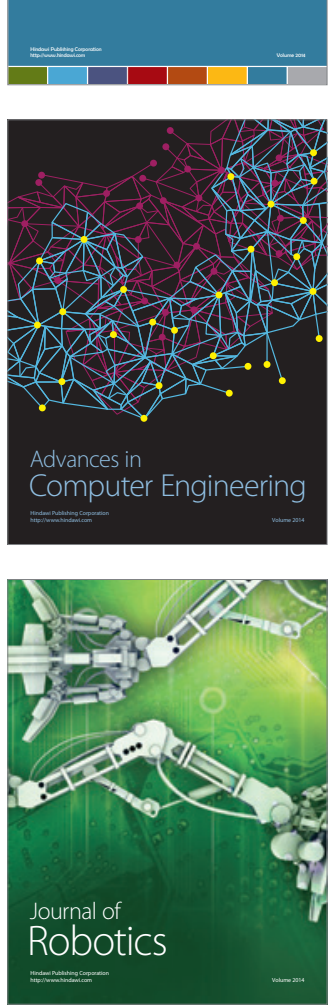
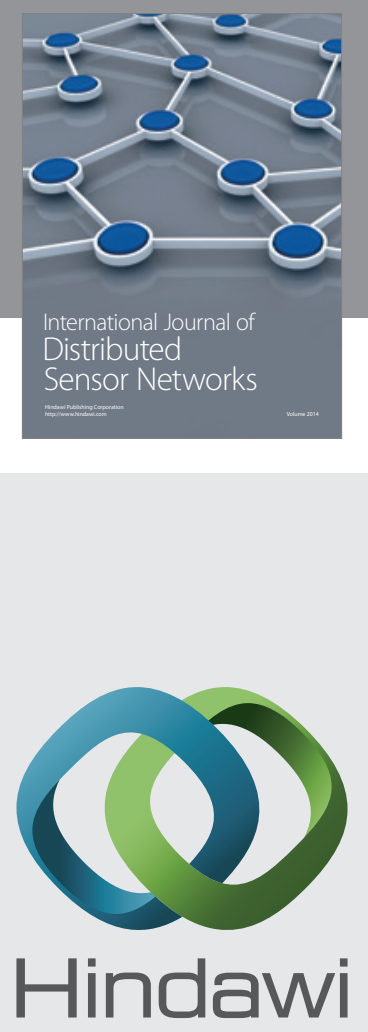

Submit your manuscripts at

http://www.hindawi.com
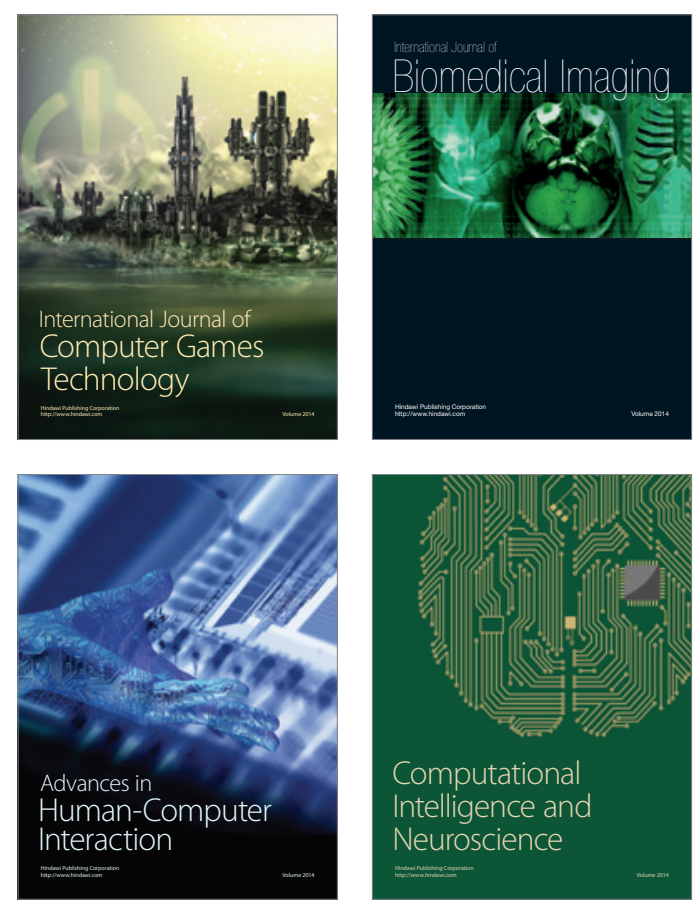
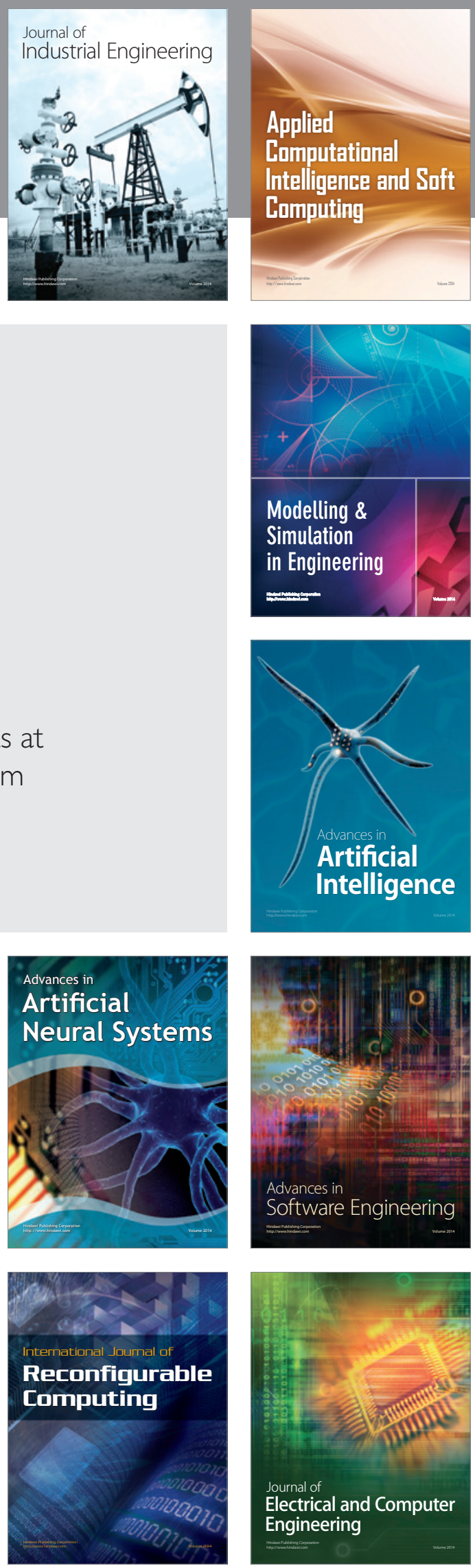